\title{
Flood damage survey after a major flood in Norway 2013: cooperation between the insurance business and a government agency
}

\author{
H. Berg ${ }^{1}$, M. Ebeltoft ${ }^{2}$ \& J. Nielsen ${ }^{2,3}$ \\ ${ }^{1}$ Norwegian Water Resources and Energy Directorate, Norway \\ ${ }^{2}$ Finance Norway, Norway \\ ${ }^{3}$ Norwegian Natural Perils Pool, Norway
}

\begin{abstract}
Results from cooperation between the insurance business and the Norwegian Water Resources and Energy Directorate on a flood damage survey after a major flood in Norway 2013 is presented, as well as results from similar cooperation after a flood in 1995. Benefits for flood risk management of including flood parameters in future damage surveys are presented.

Keywords: damage survey, flood, natural hazard, insurance, risk management.
\end{abstract}

\section{Introduction}

Data from flood events are collected by different stakeholders for different purposes. This paper presents results from cooperation on flood damage survey after a major flood in Norway in May 2013, between the insurance business and the Norwegian Water Resources and Energy Directorate (NVE). The idea is that the survey made by the insurance business for their purpose potentially could provide valuable information for other purposes within flood risk management. In the first instance the idea was to improve the basis for damage functions relevant for Norway. The paper expands on this and presents ideas for future collection of data.

\section{Flood risk management in Norway}

A White Paper with the title "How to live with the hazards" was issued by the Government in 2012, White Paper no. 15 [1]. This outlines the national policy in 
dealing with floods and landslides. The Government states that it will continue its efforts in preventing damage from floods and landslides according to a holistic approach including mapping, land use planning, protection measures, monitoring, early warning, contingency and crisis management. The Norwegian Water Resources Directorate (NVE) is the agency at directorate level responsible for coordinating the implementation of the national policy. NVE's work in preventing damage from floods and landslides is structured according to the holistic approach, in the following tasks:

- Hazard and risk mapping

- Assistance and control of land use planning in the municipalities

- Planning and construction of structural protection measures

- Monitoring and early warning: Floods, Debris flows, Snow avalanche

- Assistance to the police and municipalities in emergency situations

- Research \& Development, Communication

The White Paper [1] outlines how responsibilities for dealing with floods and landslides are distributed among the main actors. The importance of cooperation between the relevant actors is highlighted, and a national strategy for cooperation and coordination will therefore be developed.

Every municipality is obligated according to the Civil Protection Act to perform an overall Risk and Vulnerability (RAV) analysis for its territory as a basis for preparedness to deal with harmful events and for land use planning. The municipality is responsible for making sure that natural hazards are being evaluated and taken properly into account in every new development scheme, according to the Planning and Building Act.

\section{Natural hazards insurance}

In order to limit the losses to private stakeholders different compensation systems are established. One of these is the insurance against natural hazards. In Norway all buildings insured against fire are automatically insured against natural hazards such as floods, landslides and storms, according to the Natural Hazards Insurance Act. The system is based on a solidarity principle as the premium is based on the value of property and not differentiated according to risk. Damage to the building, its content as well as the garden and the courtyard adjacent to the building is covered. Insurance companies offering fire insurance are mandatory members of the Norwegian Natural Perils Pool (NNPP). The insurance companies have all contact with their policy holders, whereas the pool equalizes losses between the companies. The administration of the pool is run from a separate Pool office within Finance Norway.

Finance Norway (FNO) is the federation for banks, insurance companies and other financial institutions in Norway. Finance Norway fulfills both the business policies and employer-related cooperation in the financial sector. It is part of FNO's climate strategy to work with public authorities in the prevention of damage caused by increased frequency and intensity of natural events. This includes understanding the risk implicated by the Intergovernmental Panel on Climate Change (IPCC) climate scenarios. 


\section{Damage survey after major flood 1995 - development of stage-damage functions}

Internationally substantial work has been done on establishing stage-damage functions for floods, i.e. relations between water level during a flood and damage. There has not been much work on damage functions based on data from Norway. The residential houses in Norway outside city centers are to large extent wooden constructions. Typical residential houses before, during and after flooding is shown in figure 1. It is important to develop new or test existing damage functions on data from Norway.

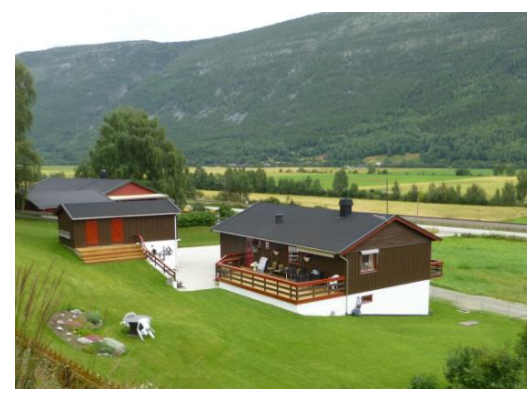

(a)

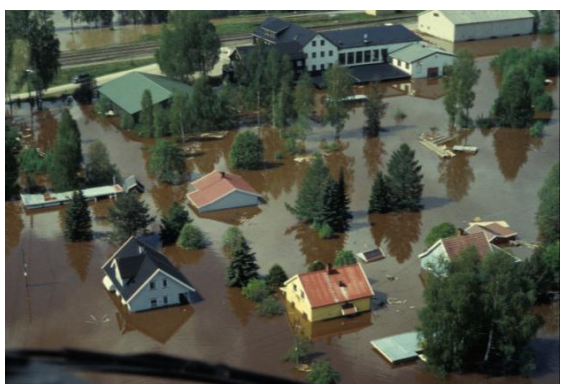

(b)

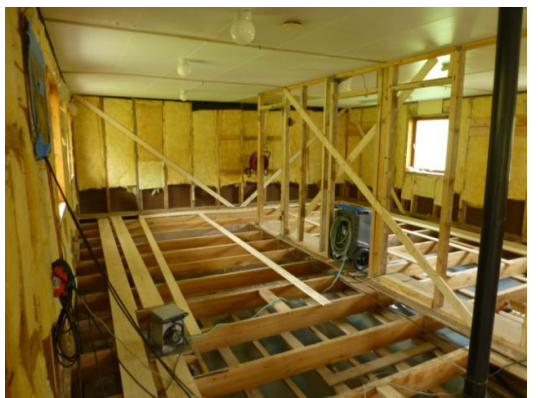

(c)

Figure 1: (a) A typical residential house; (b) flooded houses during a flood in 1995; (c) the interior of a house during repair after flood damage. (All photos: NVE.)

After a major flood in South Eastern Norway in 1995, cooperation between the Norwegian Natural Perils Pool (NNPP) and NVE was established in order to collect data on water level in buildings and the corresponding damage. The surveyors for the insurance companies were asked to register maximum water level in buildings relative to ground floor level. Wathne et al. [2] developed stagedamage functions based on a limited part of the data set (as shown in figure 2).

Some years later more of the data from the survey in 1995 was systemized and used by Gottschalk and Krasovskaia [3] in the Interreg III B project FLOWS. They established damage functions for different categories of objects, as shown in 
figure 3. Some statistical parameters related to the same data set is presented in table 1 .

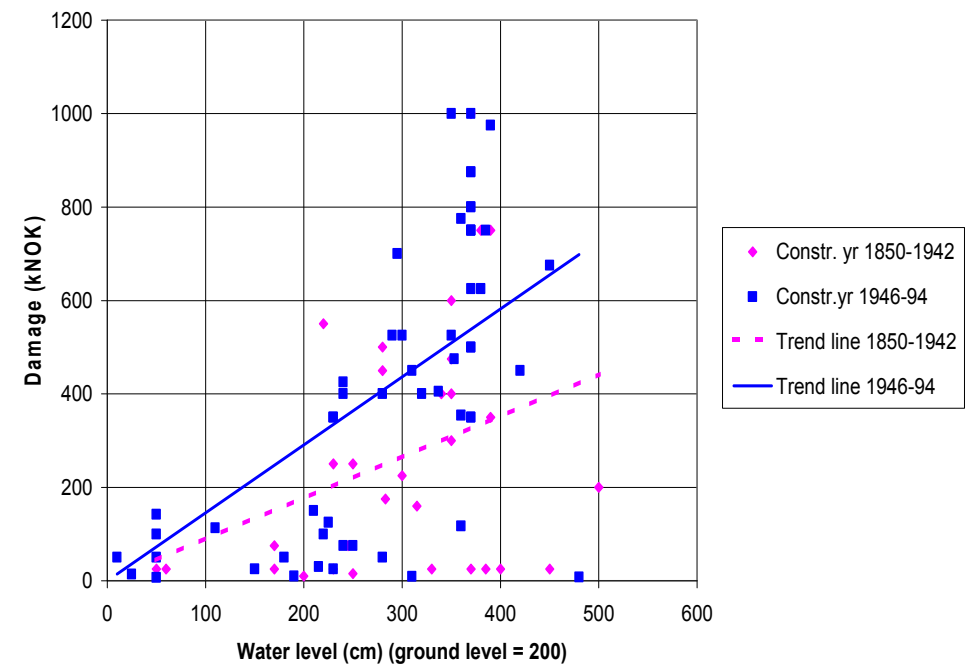

Figure 2: Individual damage cost for residential houses (detached) in terms of insurance payouts as a function of water level above basement floor (from Wathne et al. [2]).

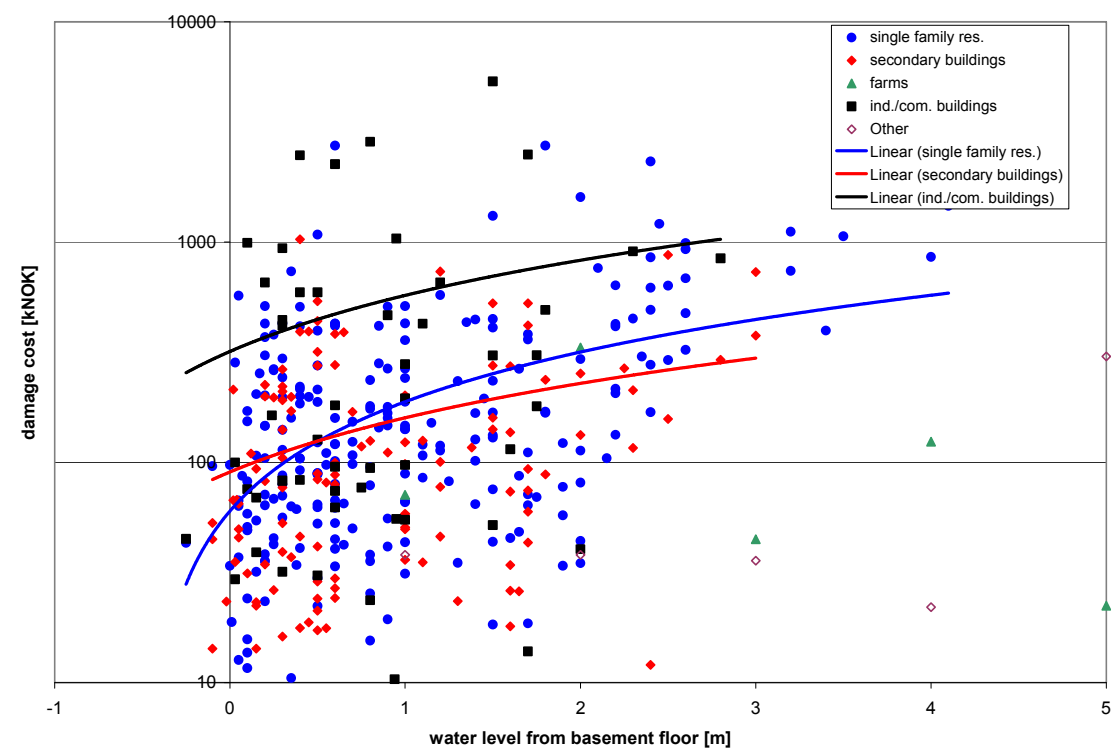

Figure 3: Scatter plot of damage for different categories of damaged objects against local water level in building (from Gottschalk and Krasovskaia [3]). 
Table 1: Statistical parameters of flood damage in kNOK for different categories of buildings (from Gottschalk and Krasovskaia [3]).

\begin{tabular}{|l|c|l|l|l|c|l|l|}
\hline Category & All data & $\begin{array}{l}\text { Single } \\
\text { family } \\
\text { residential } \\
\text { houses }\end{array}$ & $\begin{array}{l}\text { Secondary } \\
\text { houses }\end{array}$ & $\begin{array}{l}\text { Public } \\
\text { buildings }\end{array}$ & Farms & $\begin{array}{l}\text { Industrial- } \\
\text { Commercial } \\
\text { buildings }\end{array}$ & $\begin{array}{l}\text { Other } \\
\text { buildings }\end{array}$ \\
\hline $\begin{array}{l}\text { total number } \\
\text { of cases }\end{array}$ & 2296 & 607 & 211 & 97 & 649 & 359 & 373 \\
\hline $\begin{array}{l}\text { number of } \\
\text { cases with } \\
\text { complete data }\end{array}$ & 1420 & 367 & 161 & 69 & 432 & 218 & 173 \\
\hline mean & 570 & 311 & 160 & 1116 & 805 & 914 & 268 \\
\hline median & 142 & 93 & 93 & 521 & 281 & 184 & 81 \\
\hline std. dev. & 1170 & 678 & 184 & 1490 & 1333 & 1734 & 619 \\
\hline minimum & 0.1 & 1.4 & 3.5 & 11 & 0.1 & 0.1 & 795 \\
\hline maximum & 15655 & 5512 & 1029 & 10535 & 6803 & 15655 & 5512298 \\
\hline coeff. var. & 2.052 & 2.180 & 1.149 & 1.335 & 1.656 & 1.897 & 2.308 \\
\hline skewness & 4.758 & 4.737 & 2.217 & 3.995 & 2.821 & 4.524 & 5.628 \\
\hline
\end{tabular}

\section{Damage survey after the flood of 2013}

\subsection{Registration of flood parameters}

A major flood occurred in Norway late May 2013. The most severe flood and subsequent damage occurred in River Gudbrandsdalslågen and its tributaries. Figure 4 show photos of damaged buildings in the village Kvam. After the event the insurance companies immediately starts the process of assessing damage as basis for the compensation to the policy holders. For this the insurance companies hire surveyors with relevant education and experience.

Shortly after the flood, contact was established between NVE, Finance Norway and the NNPP. An agreement was made to include data on water levels in the survey, similar to what was done in 1995. Ad hoc a form was developed for the
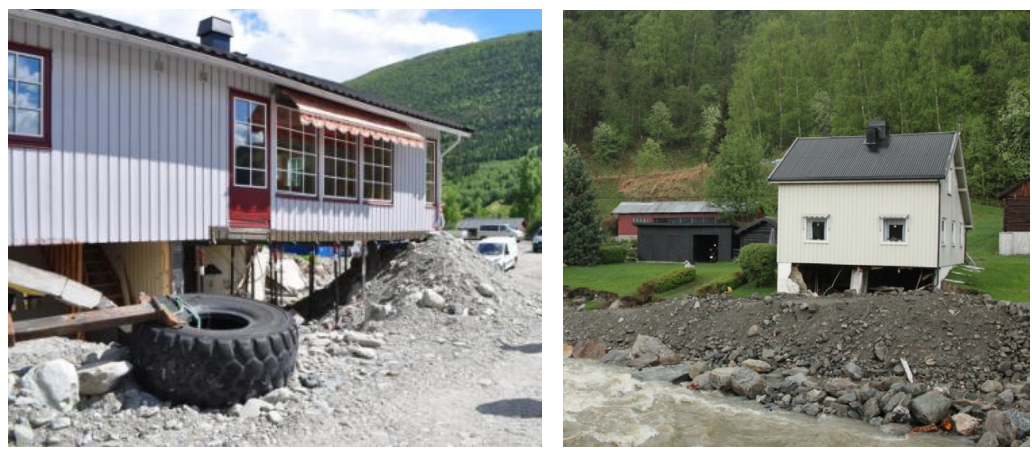

Figure 4: Damaged buildings in Kvam, June 2013. (Photos: NVE.) 
purpose and circulated to the surveyors by the NNPP, with accompanying instructions. The cost related to filling in the forms was included in the survey cost and covered by the insurance companies.

The form included a table with parameters related to the flood (see table 2). To be able to link this information to the rest of the survey, the following information was requested: surveyor name, survey no., insurance company, location and municipality no.

Table 2: $\quad$ Flood parameters included in registration form used by insurance surveyors.

\begin{tabular}{|l|l|}
\hline Building no. & ID or type of building \\
\hline Water level & $\begin{array}{l}\text { cm }+ \text { - relative to ground } \\
\text { floor level }\end{array}$ \\
\hline Basement? & yes/no \\
\hline Erosion, under-mining of building? & yes/no \\
\hline Mass deposition outside of the building? & yes/no - thickness \\
\hline $\begin{array}{l}\text { Damage due to floating objects etc. hitting the } \\
\text { building? }\end{array}$ & yes/no \\
\hline Supplementary information & \\
\hline
\end{tabular}

\subsection{Preliminary results}

As of February 2014 a total of 243 cases have been reported by the surveyors. The processing of these data is not yet completed as the compensation process is still ongoing in a substantial part of cases. Compensation paid to the policy holders so far span from more than 1 Mill NOK to 6000 NOK.

Some preliminary figures concerning the data from the forms could still be presented. Concerning water level the following data appear:

1- $270 \mathrm{~cm}$ below ground floor level: 89 cases

1- $170 \mathrm{~cm}$ above ground floor level: 85 cases

0 :

43 cases

Blank (no value): $\quad 27$ cases

Further investigation needs to be made into the cases with value " 0 " or no value. A preliminary review indicates that supplementary information in the form in some cases includes information on water level. In other cases it appears that damage was only to the garden and the courtyard.

Concerning the other parameters in the form, the following results appear as shown in table 3 .

We see from Gottschalk and Krasovskaia [3] that there is a great variability in the data set. The question is if more factors could be identified to create relations with less variability. This was the idea behind including more parameters than water level, such as erosion and mass deposition, in the form used in 2013. 
Another obvious parameter to test, is the total value of the building. This is a topic for further research.

Table 3: $\quad$ Results from damage survey related to the 2013 flood.

\begin{tabular}{|l|c|c|c|c|}
\hline & $\begin{array}{c}\text { Basement? } \\
\text { (yes/no) }\end{array}$ & $\begin{array}{c}\text { Erosion, } \\
\text { under-mining } \\
\text { of building? } \\
\text { (yes/no) }\end{array}$ & $\begin{array}{c}\text { Mass } \\
\text { deposition } \\
\text { outside of the } \\
\text { building? } \\
\text { (yes/no }- \\
\text { thickness) }\end{array}$ & $\begin{array}{c}\text { Damage due } \\
\text { to floating } \\
\text { objects etc. } \\
\text { hitting the } \\
\text { building? } \\
\text { (yes/no) }\end{array}$ \\
\hline Yes & 117 & 17 & 70 & 7 \\
\hline No & 110 & 214 & 161 & 224 \\
\hline Blank & 16 & 12 & 12 & 12 \\
\hline
\end{tabular}

\section{Damage data in flood risk management}

A key element in flood risk management is risk assessments, cost benefit analyses and other types of analyses. Assessing consequences of events is part of the analyses. Thus information from historic events provides important input to risk assessments at all levels.

Damage data at an aggregated level is important for decision making at higher, strategic levels e.g. to illustrate the size of the challenges in a national perspective. In this the existing statistics from the NNPP on damage has been important, for instance as basis for the White Paper no. 15 [1] in 2012. To be able to draw a complete picture it is important to include all types of costs. There is a lack of access to similar statistics on damage to public property and infrastructure such as roads, railroads, power grid, water supply, sewage etc.

This chapter focuses on the benefit of data at a more detailed level and in particular how data collected by the insurance business could be of value to other stakeholders in flood risk management. More and better data will improve decision making and ultimately reduce the damage caused by floods.

\subsection{Stage-damage functions}

The stage-damage functions developed based on the data from the 1995 flood, is among others useful for cost-benefit analyses related to flood protection schemes. To NVE cost-benefit analyses is key input to the decision on governmental financial support or not.

NVE's cost-benefit analyses are based on a common concept of risk among engineers: risk is a product of probability and consequences. The probability part is usually well covered, for instance through flood mapping. NVE has since 1998 produced flood inundation maps presenting areas prone to flooding with high precision based on analyses of flood frequency, hydraulic modeling and GISanalysis with a detailed digital elevation model. Limited access to data on damage 
opens for more subjective judgments of consequences and subsequently greater variability in quality of the consequence analysis. Hence, improved stage-damage functions will benefit decision making regarding flood risk by improving the quality of risk analyses. We assume this reasoning is relevant to other stakeholders investing in protection measures, such as developers and infrastructure owners.

\subsection{Detailed positioning of damage points}

Based on the cooperation from the 2013 flood, NVE and Finance Norway has started a discussion on the possibilities for including registration of flood parameters as standard in damage surveys by the insurance business. Included in this is an investigation of the advantages of more detailed positioning of damage points in map coordinates, including relating water levels to the standard map elevation basis.

NVE has highlighted that a better positioning will open for a much wider use of the data, and hence increase the value substantially. All parts of flood risk management benefit from information on events and improved mapping.

A good positioning of damage will pinpoint areas at risk and thus provide important input to the municipalities in their overall RAV-analyses. Put together such point observations could be the basis for flood event maps showing areas exposed to one particular flood. If more sophisticated mapping has not been performed, event maps are valuable for land use planning, flood protection and emergency preparedness.

Observation of water level from actual flood events is important for validation and calibration of flood models, such as the hydraulic models used in flood inundation mapping. The access and quality of calibration data in the form of observed flood levels significantly affects the quality of the maps.

Information from events in itself or via flood maps is the key for taking flood risk properly into account in land use planning. Similarly the quality of flood maps is important for the planning of protection measures. Better models could potentially lead to reduced development cost as safety/uncertainty margins could be reduced.

The models developed in the mapping process are also used during flood situations as a tool for the crisis management. Better models will accordingly improve the basis for decisions on measures to be taken during crises.

\section{Conclusions}

FNO has started a pilot project aimed at clarifying if damage data from storm water, backwater in sewer systems and natural hazards could be useful for the municipalities in their work on identifying vulnerable areas and the performance of RAV analyses. The project is due to deliver its results by the summer of 2014 .

The cooperation referred in this paper is not part of the pilot project, but stand as an example of how data from the insurance business could be used by NVE and other authorities in the prevention of flood damage. Given that the data are being used as suggested above, it could contribute to improved decisions regarding flood 
risk. Ultimately the result would be reduced damage related to flood events and/ or reduced cost for measures taken.

Registrations of more parameters related to floods, should preferably not be based on ad hoc initiatives such as in 1995 and 2013, but rather be part of standard procedures of the survey after a flood event.

Before deciding on this in any direction, more investigation is necessary on a number of issues:

- How to perform the registration in practice.

- What are the most cost-effective solutions providing sufficient quality of data

- $\quad$ Format and organization of data.

- Sensitivity of data; what could/could not be published.

Potentially such investigations could be part of a follow-up project. In any case, the processing and evaluation of the 2013-data will continue and hopefully contribute to the further investigation of these issues.

\section{References}

[1] White paper no. 15. Meld St 15 (2011-2012) Melding til Stortinget. Hvordan leve med farene-om flom og skred. In Norwegian. Ministry of Petroleum and Energy, Oslo, 2012.

[2] Wathne, M., Skoglund, M. \& Eggestad, H.O. Samfunnskostnader på grunn av flom $i$ vassdrag. HYDRA report no. R02. Norwegian with English summary. Norwegian Water Resources and Energy Directorate, Oslo, 1999.

[3] Gottschalk, L. \& Krasovskaia, I. Expected damage (risk) of flooding. Interreg IIB FLOWS report, sub project 1b, Oslo, 2006. 